УДК $8: 81: 371$

DOI: $10.18384 / 2310-712 \mathrm{X}-2015-5-68-78$

\title{
Габриелян А.A.
}

Московский государственный университет имени М.В. Ломоносова

\section{ЛЕКСИКО-СЕМАНТИЧЕСКОЕ ПОЛЕ ЭМОЦИОНАЛЬНЫХ КОНЦЕПТОВ SMILE, LAUGH В АНГЛИЙСКОМ ЯЗЫКЕ}

Аннотация. В статье приведены результаты исследования лексико-семантического поля эмоциональных концептов smile, laugh. Проводится анализ лексем, репрезентирующих концепты, и выявляется специфика вербализации этих ментальных образований. Рассмотрены наиболее яркие номинанты, иллюстрирующие влияние экстралингвистических фракторов и демонстрирующие многообразие репрезентации концептов. Привлечение данных английских словарей позволяет выделить ядро и периферию концептов smile, laugh для их лексического описания на всех уровнях: от слов и устойчивых словосочетаний до фразеологизмов.

Ключевые слова: эмоциональный концепт, лексико-семантическое поле, вербализация, репрезентация концепта, ядро и перисрерия концепта.

\section{A. Gabrielyan \\ Lomonosov Moscow State University \\ SEMANTIC FIELD OF THE EMOTIONAL CONCEPTS SMILE, LAUGH IN THE ENGLISH LANGUAGE}

Abstract. The aim of the present article is the study of a lexical-semantic field of the emotional concepts smile, laugh. Through the analysis of the lexemes representing the concepts the peculiarities of these verbalized mental constructions are revealed. Consideration has been given to the most vivid representations which illustrate the influence of extralinguistic factors and showcase the variety of the concepts' verbalization. The data taken from the dictionaries will make it possible to mark the kernel and the periphery of smile, laugh for the lexical description of the specified concepts at all levels, from words and collocations to idioms and phraseological units. Key words: an emotional concept, semantic field, verbalization, concept representation, a kernel and periphery of the concept.

Улыбку как ментальное образование и эмоциональный концепт регулятивного типа можно отнести к универсалиям, так как она наднациональна и является общечеловеческим символом [2, с. 30]. Улыбка предстаёт важнейшим концептом в западной культуре и неким атрибутом, выражающим оп-

(c) Габриелян А.А., 2015. тимизм, доброжелательное отношение, вежливость и благосклонность [6, c. 241]. Изначально она трактуется как базовая человеческая эмоция, а также элемент мимики, позволяющий выразить возникшую эмоцию, направленную вовне. В основе генерирования эмоций лежат рефлексы и инстинкты, универсальные для всех представите- 
лей культур. Несмотря на это, языковое выражение тех или иных эмоций может варьироваться в разных лингвокультурах.

Актуальность исследования обоснована его включенностью в парадигму лингвокультурологических исследований: изучение языкового выражения улыбки как неотъемлемого атрибута общения позволит достичь успеха в межкультурной коммуникации.

Как известно, улыбка предстаёт очень многогранным явлением и, в зависимости от контекста и ситуации, может по-разному трактоваться: искренняя улыбка, дежурная улыбка, наигранная улыбка. Важным представляется выделить номинанты, максимально полно выявляющие особенности выражения в английском языке и позволяющие судить о культурных различиях и о значении улыбки и смеха в данной культуре.

Эмоция как существенный компонент культуры вербализуется при помощи определённых эмотивных знаков языка [8, с.47]. Кроме того, при выражении эмоции всегда очевидна оценка говорящего, так как при помощи эмоции демонстрируется отношение человека к какому-либо явлению.

Концепты smile и laugh отнесены к одному классу, так как тесно взаимосвязаны и образуют единую группу. Для выявления особенностей вербализации концептов smile, laugh в английском языке проведём анализ их основных номинантов, двигаясь от центра к периферии поля. В исследовании были использованы методы концептуального анализа и построения лексико-семантического поля. Отметим, что моделирование поля в нашем ис- следовании предполагает семантикокогнитивный подход с привлечением данных 12 английских и американских словарей разных типов (толковых и фразеологических словарей, словарей сленга и словарей сочетаемости $[10 ; 11$; $12 ; 13 ; 14 ; 15 ; 16 ; 17 ; 18 ; 19 ; 20 ; 21])$ для представления наиболее полной картины концептов. Именно репрезентанты, находящиеся на разных лексических уровнях, позволят определить особенности актуализации концептов в английском языке для выявления специфики их вербализации. Ряд учёных определяют семантическое поле как совокупность языковых единиц, связанных общностью содержания и отражающих сходство явлений [3, c. 99]. Таким образом, исследование предполагает изучение слов и словосочетаний, входящих в тематический ряд «улыбка, смех» и относящихся к соответствующей области значений [1].

Обратимся к данным словарей английского языка и определим ядро и периферию концепта. Становится очевидным, что слово-концепт smile и слово-концепт laugh - доминанты лексико-семантического поля, передающие значения наиболее однозначно и используемые постоянно [9, с. 66]. Известно, что отдалённые от ядра коллокации находятся на периферии поля и дополняют картину вербализации базовой человеческой эмоции в английском языке: к ним относятся номинанты разных частей речи, существительные, прилагательные, наречия, словосочетания разных типов (атрибутивные, предикативные, объектные) и ономатопические образования. Эти единицы расположены слоями вокруг ядра. Таким образом, исследование распадается на две части: 
1) анализ лексико-семантической группы "smile" (репрезентанты to smile, to grin, to smirk, to beam, to leer, to simper, to sneer);

2) анализ лексико-семантической группы "laugh" (to laugh, to giggle, to cackle, to chuckle, to guffaw, to titter, to fleer, to snigger, to mock, to jeer, to crack up).

Начнём движение в сторону периферии от ядерных выражений с номинантами smile и laugh. Основной репрезентант лексико-семантической группы smile - лексема smile, представленная существительным или глаголом, причём как существительное она выступает в большом количестве лексических коллокаций. Репрезентация smile насчитывает 120 примеров узуальных словосочетаний, среди которых 46 атрибутивных, 11 предикативных словосочетаний, 8 метафор и 2 фразовых глагола. В рамках данной статьи нам удастся представить лишь наиболее яркие примеры сочетаемости. В таблицах 1 и 2 демонстрируются виды улыбок и дифференцируются признаки классификации с учётом эмоционально-оценочных коннотаций - положительной (таблица 1) и отрицательной (таблица 2):

Тот факт, что в языке представлены как положительная, так и отрицательная коннотация характеристик концепта smile, показывает, что улыбка многообразна и важна в процессе общения. Если в таблице 1 улыбка отражена как символ доброжелательно-

Таблица 1

\section{Положительная коннотация}

\begin{tabular}{|l|l|}
\hline Красивая улыбка & $\begin{array}{l}\text { a bright smile, a sunny smile, } \\
\text { a cheerful smile, a gentle smile }\end{array}$ \\
\hline Одобрительная / добрая улыбка & a warm smile \\
\hline Загадочная улыбка & enigmatic smile \\
\hline Широкая улыбка & a broad smile, a wide smile, a happy smile \\
\hline Обаятельная улыбка & a winning smile, a charming smile \\
\hline Обезоруживающая улыбка & a disarming smile \\
\hline Ослепительная улыбка & a radiant smile, a dazzling smile \\
\hline
\end{tabular}

Таблица 2

\section{Отрицательная коннотация}

\begin{tabular}{|l|l|}
\hline $\begin{array}{l}\text { Фальшивая / неискренняя / дежурная / } \\
\text { натянутая улыбка }\end{array}$ & $\begin{array}{l}\text { a forced smile, a polite smile, a phoney smile, a ready } \\
\text { smile }\end{array}$ \\
\hline Мрачная / грустная улыбка & $\begin{array}{l}\text { a grim smile, a rueful smile a sad smile, a humourless } \\
\text { smile, a joyless smile, a mirthless smile }\end{array}$ \\
\hline Язвительная / саркастическая улыбка & a sardonic smile, a wry smile \\
\hline Заговорщическая улыбка & a conspiratorial smile \\
\hline Застенчивая улыбка & a shy smile, a sheepish smile \\
\hline Надменная улыбка & a supercilious smile \\
\hline Виноватая улыбка & an apologetic smile \\
\hline Кривая улыбка & a wry smile, a lopsided smile, a crooked smile \\
\hline Беззубая улыбка & a toothless smile \\
\hline
\end{tabular}


сти, оптимизма, красоты, радости, то в таблице 2 описаны улыбки, которые по своей семантике противоречат изначальной категории значения. Такое расхождение можно объяснить рядом факторов: с одной стороны растущая популярность «улыбки» как атрибута делового общения и преуспевания, с другой - стремление намеренно скрыть эмоции от собеседника. Такая тенденция прослеживается и в предикативных словосочетаниях, в которых можно выявить 2 положительные (улыбаться - to wear a smile, to have a smile, to flash a smile; улыбаться в ответ to return a smile) и 2 отрицательные коннотации (скрывать улыбку - to hide a smile и выдавить улыбку - to repress a smile). Носителей английского языка отличает образность мышления, что и отражено в ряде метафор движения, в которых улыбка «оживает»: улыбка исчезает - a smile fades, a smile vanishes; улыбка замирает - a smile freezes; улыбка возникает - a smile crosses something, a smile grows, a smile spreads across / over something. Кроме того, яркую лексическую валентность подтверждают и 35 предикативных словосочетаний с наречиями, а идиоматичность языка - 10 идиом, кпримеру, радостноулыбаться to be all smiles, удача улыбнулась - a smile of fortune, улыбаться до ушей - to smile from ear to ear. Значения ульбки передают всю палитру оттенков, яркую и многообразную. Заметим, что лексические коллокации представляют собой языковые сочетания знаков, отражающих наиболее важные и ценные для того или иного этноса элементы мировидения [4, с. 162]. Немаловажно и устойчивое словосочетание keеp smiling, некий девиз американского народа, который призывает всех улыбаться, несмотря на проблемы и трудности. Производные от smile репрезентанты - smilingly (наречие) и знаменитый «смайлик» a smiley, служащий обозначением улыбки в электронных сообщениях.

На следующем этапе изучения лексической валентности номинантов первой лексико-семантической группы рассмотрим лексему grin (ухмылка), одну из самых частотных (77 репрезентаций) в лексико-семантическом поле концептов. В приведённых ниже таблицах (таблица 3 и таблица 4) охарактеризуем репрезентанты с точки зрения положительной и отрицательной оценок.

Сопоставляя данные двух таблиц (табл. 3 и табл. 4), мы видим, что отрицательных коннотаций (10 значений) значительно больше, чем положительных (6 значений), что говорит о специфике восприятия grin в английском языке: это, прежде всего, ухмылка. Метафоры движения (9 номинантов) c grin также говорят о многообразии лексической репрезентации и демонстрируют близость качественных характеристик с лексемой smile: a grin broadens, a grin grows broader / wider, a grin widens / appears / spreads across or over smth - улыбка / ухмылка возникает / растягивается / возникает, a grin disappears / fades - улыбка / ухмылка исчезает). Номинант grin входит и в состав фразовых глаголов: to grin back (ответить улыбкой), to grin at somebody (улыбаться кому-либо), to grin with pleasure (радостно улыбнуться). Отметим, что некоторые словосочетания коррелируют со словосочетаниями, в которых присутствует smile, особенно атрибутивные и предикативные (21 репрезентант), что объясняется сино- 
Положительная коннотация

\begin{tabular}{|l|l|}
\hline Улыбка во весь рот & $\begin{array}{l}\text { a big grin, a broad grin, a huge grin, a large } \\
\text { grin, a wide grin, a toothy grin }\end{array}$ \\
\hline Дружелюбная улыбка & a friendly grin \\
\hline Одобрительная, благосклонная улыбка & a sympathetic grin, a knowing grin \\
\hline Заразительная улыбка & an infectious grin \\
\hline Весёлая улыбка & a boyish grin \\
\hline
\end{tabular}

Таблица 4

\section{Отрицательная коннотация}

\begin{tabular}{|l|l|}
\hline $\begin{array}{l}\text { Сдержанная, хилая, едва заметная } \\
\text { улыбка }\end{array}$ & $\begin{array}{l}\text { a faint grin, a feeble grin, a lazy grin, a sickly } \\
\text { grin }\end{array}$ \\
\hline Глупая ухмылка & a foolish grin, a goofy grin, a silly grin \\
\hline Мрачная / печальная / грустная улыбка & a grim grin, a rueful grin, a mirthless grin \\
\hline $\begin{array}{l}\text { Злорадная / наглая / злая / злобная } \\
\text { ухмылка }\end{array}$ & $\begin{array}{l}\text { a cheeky grin, an impish grin, a sardonic grin, } \\
\text { an evil grin, a wicked grin, a wolfish grin }\end{array}$ \\
\hline Застенчивая / скромная ухмылка & a bashful grin, a sheepish grin \\
\hline Кривая ухмылка & a wry grin, a crooked grin, a lopsided grin \\
\hline Усмешка над самим собой & a self-mocking grin \\
\hline Сумасшедшая / безумная ухмылка & an insane grin, a manic grin \\
\hline Отвратительная ухмылка & a hideous grin \\
\hline «Редкозубая» / беззубая улыбка & a gap-toothed grin, a toothless grin \\
\hline
\end{tabular}

нимичностью номинантов grin и smile и близостью их значений. Лексема grin отражена и во фразеологизмах (4 идиомы), причём некоторые из них даже передают реалии британской культуры, к примеру, в идиоме to grin like a Cheshire cat Чеширский кот - персонаж сказки Льюиса Кэролла (здесь роль сыграл экстралингвистический фактор, который обусловил появление выражения в языке).

Далее рассмотрим лексему smirk, входящую в состав атрибутивных (an arrogant smirk / a self-satisfied smirk - caмодовольная, надменная улыбка, ухмылка, насмешка, деланная или глупая улыбка; a knowing smirk / a patronizing smirk - понимающая, снисходительная улыбка / ухмылка) и объектных сло- восочетаний (to have a smirk, to give a smirk - ухмыляться / самодовольно улыбаться; to conceal a smirk, to hide a smirk - скрывать ухмылку / самодовольную улыбку) [16]. Обнаружена одна метафора движения - a smirk flickers (усмешка возникает / вспыхивает). Отметим, что номинант smirk содержит оттенок «усмешка», и, как правило, здесь семантика подвержена влиянию отрицательных коннотаций: «сатирический», «иронический», «показной / претенциозный». Производными считаются прилагательное smirking, наречие smirkingly и существительное a smirker.

Рассмотрим следующую лексему лексико-семантической группы «улыбка»: to beam. Из предикативных слово- 
сочетаний назовём to beam triumphantly (радостно улыбаться), из объектных to win a forgiving beam (заслужить снисходительную улыбку, буквально - завоевать улыбку снисхождения) [16], среди идиом - to scowl and beam (хмуриться и улыбаться) [17]. Фразовый глагол, синонимичный вышеперечисленным словосочетаниям, - to beam at (ласково и приветливо улыбаться). Номинант содержит положительную оценку. Очевидно, что в данном случае лексическая валентность у лексемы невысокая (7 репрезентаций).

Обратимся к устойчивым словосочетаниям с лексемой sneer («усмешка», чаще всего употребляется с отрицательной коннотацией), относящейся к лексико-семантической группе «улыбка», и выделим атрибутивные (an arrogant sneer - высокомерная улыбка, a faint / slight sneer - едва заметная усмешка) и объектные (to give a sneer презрительно усмехаться, to hide a sneer - скрывать презрительную усмешку) [16]. У ещё одного номинанта leer коллокация представлена лишь одной лексической единицей, которая в одной из коннотаций выступает как «хитро смотреть и улыбаться» - to leer an eye at (буквально: бросить хитрый взгляд). Обратим внимание и на коллокации с лексемой simper: to simper consent (выразить согласие улыбкой) и to simper an excuse [16].

Для выявления коллокаций с лексемой laugh, относящейся ко второй лексико-семантической группе "laugh", обратимся к лексикографическим данным. Если исходить из данных словарей и обратиться к атрибутивным словосочетаниям, то становится очевидным, что многие виды смеха по качественным характеристикам совпа- дают со словосочетаниями, которые употребляются с существительным $a$ smile, что говорит о взаимосвязи обозначенных концептов. Столь значительное количество идиом с номинантом laugh (60 лексических единиц) позволяет прийти к выводу о том, что в сознании носителей эта репрезентация играет важную роль и окрашена палитрой самых разных оттенков: от положительной коннотации (весёлый / радостный смех - a loud laugh, a big laugh, a great laugh, a hearty laugh) до отрицательной (a nervous laugh, a bitter laugh, a cynical laugh). Из других репрезентаций можно назвать объектные с laugh (рассмеяться - to give a laugh, to let out a laugh; разразиться / залиться смехом - to burst out laughing и покатиться со смеху - to howl with laughter). Существительное a laugh соотносится с синонимом и однокоренным существительным laughter, являющимся не менее репрезентативным номинантом. Бытует мнение, что словосочетания с номинантом laugh практически устарели, и молодёжь их не использует. Если в речи и употребляют одно из существительных, то более распространённым является laughter. Некоторые используют такие словосочетания с существительным $a$ laugh, что не приветствуется носителями современного английского языка, в особенности американского варианта. Из идиом выделим laughter lines, т.е. 'морщинки, появляющиеся вокруг глаз от смеха', a laugh track, 'смеховая дорожка, используемая в телевизионных шоу для воссоздания смеха в аудитории во время передачи' [17]. Нечто несмешное называют no laughing matter. Есть составной термин laughing gas («веселящий газ»), laughing jackass, 
обозначающий австралийского зимородка (птицу), и laughing frog (озерная лягушка). Из словосочетаний, относящихся к разговорному стилю, назовём laughing water - шампанское. Неудивительно, что существует и разговорный вариант названия психиатрической больницы с коннотацией «психушка» laughing academy или laughing farm (сленг) [19]. А объект для насмешек называют a laughing stock (то же, что шут гороховый). Что касается паремиологии, то на данном уровне можно отметить пословицу "Не who laughs last laughs longest" (Хорошо смеётся тот, кто смеётся последним) и поговорку "Laughter is the best medicine" (Смех лучшее лекарство) [17; 18]. Можно предположить, что смех воспринимается носителями языка как положительное явление, в том числе с точки зрения благотворного влияния на здоровье человека.

Вокруг доминанты группируются наиболее близкие к ней репрезентанты, которые составляют ядро поля это синонимический ряд так называемых laughter verbs, глаголов смеха: to laugh, to cackle, to chuckle, to giggle, to snigger, to mock, to fleer, to simper, to titter, to guffaw. Обратим внимание на то, что большая часть из них являются ономатопическими образованиями, что говорит о некой роли звукосимволизма и непроизвольной природе образования слов от звучания. Согласно данным словарей английского языка $[10 ; 11 ; 12$; $14 ; 15]$, по дефинициям данных глаголов можно сделать вывод, что глаголы, действительно, образуют синонимический ряд, а именно «структурно-семантическое объединение слов, элементы которых максимально близко онтологически связаны друг с другом» [4, c. 103]. Более того, существуют явные оттенки значений, которые говорят о некоторой градации смеха: to laugh смеяться; to cackle (to laugh in a loud unpleasant way, making short high sounds) - гоготать, ржать, хохотать; to chuckle (to laugh quietly) - хихикать, посмеиваться, усмехаться; to giggle (to laugh quickly, quietly, and in a high voice, because something is funny or because you are nervous or embarrassed) - хихикать, посмеиваться, глупо смеяться, нервно смеяться; to mock (to laugh at someone or something and try to make them look stupid by saying unkind things about them or by copying them) - высмеивать, издеваться, передразнивать, осмеивать, глумиться, потешаться; to snigger (to laugh quietly in a way that is not nice at something which is not supposed to be funny) - посмеиваться, сдавленно хихикать, злорадно посмеиваться; to fleer (to laugh or grimace in a coarse derisive manner) - презрительно улыбаться, усмехаться, насмехаться, скалить зубы; to simper (to smile in a silly annoying way) - самодовольно или глупо улыбаться, ухмыляться, жеманно улыбаться; to titter (to laugh quietly in a high voice, especially because you are nervous) - хихикать и нервно смеяться; to guffaw (to laugh loudly) - гоготать, хохотать, to jeer (to laugh or scoff at a person or thing) глумиться, насмехаться, to crack up (to suddenly start laughing) - взрываться от смеха, смеяться до упаду. Исходя из данных словарей $[10 ; 11 ; 12 ; 13 ; 14 ; 15$; $16 ; 19]$, мы пришли к выводу о том, что в изучаемом лексико-семантическом поле действуют синонимические связи, которые соединяют слова с разными коннотациями и оттенками значений улыбки и смеха. Специфическую особенность поля представляет собой и 
большое количество синонимичных номинантов с элементом значения «усмехаться», и разные оттенки значений «смеяться», которые переводятся и как «громко смеяться», и как «тихо смеяться», и как «нервно смеяться», и как «зловеще смеяться», и как «хихикать» или «гоготать».

Выделим основные словосочетания с лексемами с оттенками значения «смех», принадлежащими к лексико-семантической группе «смех». В объектных словосочетаниях с номинантом giggle (28 лексических репрезентанций) giggle тяготеет к laugh и smile, и в некоторых случаях выражения повторяются. Более того, согласно словарю сленга, психиатрическую больницу наряду с laughing academy стали называть также giggling academy. Что касается шампанского, то его называют giggle јиiсе (разг.) Можно отметить производные: прилагательное giggling, существительное - giggler ('часто смеющийся человек') и прилагательное giggly.

К лексико-семантической группе «смех» относится ещё одна лексема cackle (хохот, гоготанье), представленная в объектных словосочетаниях to give a cackle, to let out a cackle, to give a cackle of laughter (захохотать, гоготать), а также в идиомах “cut the cackle!” (хватит болтать!), “What a cackle she is!" (Какая же она болтушка!) и a cackling witch (хохочущая ведьма) [17]. Необычной является идиома to cut the cackle (slang) сокращённый вариант идиомы cut the cackle and come to the hosses (Хватит болтать! Ближе к делу!) [17]. Также имеет смысл выделить выражение a cackle of laughter (взрыв смеха) и прилагательное cackling. Ещё одним номинантом лексико-семантической группы «смех» выступает chuckle (18 единиц). В словаре сленга зарегистрировано слово $a$ chucklehead, что переводится как «болван» [19].

Лексема mock участвует в немалом числе устойчивых словосочетаний: объектном to make a mock of someone - 'высмеивать кого-либо', предикативном to mock bitterly ('злобно подшучивать, насмехаться'), to mock ruthlessly ('безжалостно высмеивать кого-либо'), to mock scornfully ('презрительно насмехаться'), становится фразовым глаголом to mock at somebody ('насмехаться над кем-либо') и to mock up ('подделывать что-либо') [16]. Среди идиом стоит назвать такие как to mock with smile - презрительно улыбнуться; to mock fears - издеваться над чьими-либо страхами; mock jewelry поддельные драгоценности [17]. Что касается существительного mockery, то оно образовано от лексемы mock и буквально означает насмешку, осмеяние, пародию. Последний элемент значения присутствует у образованного от данной лексемы слова mockingbird (пересмешник, 'североамериканская или австралийская птица, которые копирует звуки других птиц').

Следующий номинант данной лексико-семантической группы - to guf$f a w$, который представлен в словарях лишь одним фразовых глаголом to guffaw at somebody. Лексему to titter иллюстрирует такое словосочетание, как to raise a titter, и фразовый глагол to titter at (somebody). Можно также образовать прилагательное tittering и наречие titteringly.

To fleer как лексема существует только как глагол, в одной из коннотаций обозначающий «презрительно улыбаться и скалить зубы». Интересна 
и лексема snigger, которая пишется так в британском варианте английского языка. В американском диалекте написание отлично - snicker. Следует отметить выражения to snigger at / about, to have a snigger, a snicker of ridicule. Из оставшихся номинантов выделим to jeer, который часто употребляется в качестве фразового глагола to jeer at (можно образовать и прилагательное jeering), а также to crack up (to suddenly start laughing a lot). Немаловажными являются и ономатопические образования, которые также можно отнести к лексико-семантической группе «смех»: ha-ha или ha ha ('звук смеха', коннотация как положительная, так и отрицательная), которое встречается в словосочетаниях ha-ha bird (kookaburra, австралийская птица), ha-ha ('стакан пива', сленг, амер. вариант англ.). Ономатопическим является и выражение huh-huh-huh. Следует отметить, что в основе звукосимволизма и ономатопических образований «лежат физические свойства» $[8$, c. 106]. Такой оттенок приобретается в процессе передачи эмоции. Ряд слов, которые «мы ныне не ощущаем как звукоподражательные», могут быть возведены «к такой некогда существовавшей фонетической форме, которая даёт серьёзное основание видеть их происхождение в подражании естественным звукам» $[7$, с. 31], - таковым является глагол laugh.

В результате данного исследования были выявлены лексические единицы на разных уровнях для проведения концептуального анализа. Лексические единицы, репрезентирующие концепты smile, laugh, отражают разные коннотации - как положительные, так и отрицательные.
Исходя из проанализированных коллокаций, представляющих ядро и периферию эмоциональных концептов smile, laugh, можно прийти к выводу, что эмотивная лексика и фразеология обусловлены экстралингвистическими факторами и передают особый тип мышления в определённой лингвокультуре. Столь насыщенное лексико-семантическое поле и столь богатый материал позволяют нам судить о важности концептов smile, laugh и их вербализации в английском языке: в качестве примеров приведены большое количество оттенков значений, градация синонимического ряда и различные коннотации. Неслучайно в американской лингвокультуре smile и laugh являются неким атрибутом и американской речевой культуры: согласно национальным представлениями, американцы оптимистичны, жизнерадостны и не жалуются. Они постоянно демонстрируют оптимизм, открытость, успех, радость в общении [8, с. 291]. Известно, что «американец в 95 \% улыбается не потому, что ему лично в данный момент приятно, а для того, чтобы сделать приятное речевому партнёру» [8, с. 305]. Таким образом, лексико-семантическое поле выражено двумя лексико-семантическими группами и синонимическим рядом, составляющим поле, а также разными типами устойчивых словосочетаний. Чем ярче картина вербализации концепта, тем важнее и значимее данная человеческая эмоция для определённого этноса. Неслучайно говорят, что слово - «это кусочек действительности», который проходит через сознание человека и, отражаясь, приобретает особые черты, характерные для данного мировоззрения и сознания 
[5, с. 27]. Американцы всегда считаются улыбающимися, а «голливудская улыбка» - их символом. В британской лингвокультуре улыбка является в большей степени вежливым вербальным знаком, призванным продемонстрировать благосклонность и доброжелательность. Отметим, что слово отражает видение реальности, которое приписано сознанием и представлением о предмете или явлении [7, с. 24]. Этноспецифичность смеха и улыбки проявляется не только во внушительном количестве, в обширном семантическом содержании и форме его номинантов, но также в особенностях их лексической валентности, которая позволяет выявить особенности сочетаемости. Анализируя единицы лексикосемантической группы «улыбка, смех», мы приходим к выводу о том, что они часто употребляются в коммуникации. Коммуникативная функция очевидна: синтагматические связи номинантов говорят об их частотности и значимости в лингвокультуре. Несмотря на то что изучаемые "улыбка» и "смех» являются базовыми человеческими эмоциями, их языковое воплощение в любом языке уникально и имеет ряд особенностей.

Данные, которые были получены в ходе проведённого анализа лексикосемантического поля smile, laugh, позволяют сделать вывод о том, что smile, laugh - ключевые эмоциональные концепты западной культуры, в особенности находящие своё отражение в американской лингвокультуре - от нейтральной лексики до разговорного стиля. Благодаря различиям значений, передаваемым в словосочетаниях с номинантами изучаемого поля, удалось определить трудноуловимые или спе- цифические оттенки, которые носители вкладывают в эмоцию. Лексическая валентность репрезентаций данного концепта показывает многообразие улыбки и смеха в языке и в культуре и их различные виды. Более того, лексико-семантический анализ позволяет не только судить о лексической репрезентации и о том, как выражена эмоция, но и понять, каковы реальные переживания носителя языка и что он чувствует в процессе отражения эмоции посредством словесного знака. Таким образом, языковое воплощение реализует в себе элементы лингвокультуры.

\section{ЛИТЕРАТУРА:}

1. Ахманова О.С. Словарь лингвистических терминов. М., 1966. [Электронный ресурc]. URL: http://www.classes. ru/grammar/174.Akhmanova/ (дата обращения: 05.03.2015).

2. Карасик В.И. Языковые ключи. М.: Гнозис, 2009. 406 с.

3. Кобозева И.М. Лингвистическая семантика. М.: Эдиториал УРСС, 2000. $352 \mathrm{c}$.

4. Красавский Н.А. Эмоциональные концепты в немецкой и русской лингвокультурах. М.: Гнозис, 2008. 374 с.

5. Сепир Э. Избранные труды по языкознанию и культурологии. М.: Прогресс; Универс, 1993. 656 с.

6. Тер-Минасова С.Г. Язык и межкультурная коммуникация: учебное пособие. М.: МГУ, 2004. 352 c.

7. Тер-Минасова С.Г. «Мысль изреченная есть ложь...» // Ценности и смыслы. 2012. № 1 (17). С. 22-33.

8. Шаховский В.И. Лингвистическая теория эмоций. М.: Гнозис, 2008. 416 с.

9. Щур Г.С. Теория поля в лингвистике. М.: Наука, 1974. 254 с.

10. Cambridge Advanced dictionary. Cambridge University Press, 2005. 1572 p.

11. Collins dictionary. Fourth edition. Pub- 
lished by Glasgow, HarperCollins, 1999. $1740 \mathrm{p}$.

12. Longman Contemporary English dictionary. Pearson Education Limited, 2003. $1950 \mathrm{p}$.

13. Modern English-Russian dictionary. By V.K. Mbller. Moscow: Russky yazik media, 2007. $945 \mathrm{p}$.

14. NTC's American English learner's dictionary. Illinois, NTC / Contemporary Publishing Group, 1998. 1104 p.

15. Oxford American dictionary. Oxford University Press Inc., 1980. 816 p.
16. Oxford collocations dictionary. Oxford University Press, 2002. 897 p.

17. Oxford dictionary of English idioms. Oxford University Press, 1993. $748 \mathrm{p}$.

18. Roget's Thesaurus of English words and phrases. London: Chancellor Press, 1986. $736 \mathrm{p}$.

19. Smaller slang dictionary. By E. Partridge. NY, 1961. $204 \mathrm{p}$.

20. The New Partridge Dictionary of Slang and Unconventional English. Vol. 1. London: Routledge, 2006. 2216 p.

21. The Oxford Senior Dictionary. Oxford University Press, 1982. 768 p. 